\title{
CERN to open US talks on collider project
}

Washington \& London. The director general of the European Laboratory for Particle Physics (CERN), Christopher LlewellynSmith, is to open talks with US government officials in Washington early next month about a possible US contribution to the proposed Large Hadron Collider (LHC).

According to officials of the US Department of Energy (DoE), the meeting will allow CERN formally to tell the United States what form it would like such a contribution to take. The US negotiating team, led by Martha Krebs, director of the DoE's Office of Energy Research, is not expected to bring its own proposals to the meeting, but to respond to those of CERN.

The US team will also include representatives of the National Science Foundation, the White House Office of Science and Technology Policy and the State Department. The meeting was to have taken place earlier this month, but was postponed because of the US government shutdown.

The meeting is the first of what may turn out to be a lengthy series. The DoE is cutting many of its own domestic programmes, and has little room for manoeuvre in supporting an overseas facility.

At the same time, however, the DoE budget for high-energy physics - the likely source of any LHC funding - has not been cut. A panel chaired by Sidney Drell, deputy director of the Stanford Linear Accelerator Center (SLAC) in California, last year reported that the United States could afford a substantial contribution to LHC starting in the 1998 financial year, when commitments to some domestic projects would start to tail off (see Nature 369, 266; 1994).

Drell foresaw a US contribution of $\$ 400$ million between 1998 and 2003. He also said participation in the LHC would require the public endorsement of the president of the United States, which has not been forthcoming. At next month's meeting, LlewellynSmith is expected to lay out his proposals on how the United States could contribute to the LHC at a level commensurate with the expected participation of US physicists in experiments on the facility.

There seems to be general agreement that the bulk of any US contribution to the LHC would be spent in US laboratories, such as the Brookhaven National Laboratory and Fermilab. There is also confidence that the United States can be persuaded that its involvement in the project will provide some crucial 'added value' to the whole project.

Speaking at a meeting in Italy three weeks ago (see Nature 378, 226; 1995), Llewellyn-Smith said that the decision to build the LHC in two stages, with the final completion date determined by the levels of contribution from non-member states, offered an additional incentive for such countries to join. "We can now say to them 'If you come in, your contribution will allow us to get more value for money," he said.

But there is also concern among CERN officials that, if any eventual US contribution is distributed between the costs of the main accelerator and the additional costs of experimental detectors in the same proportion as followed by most large European states - namely two to one - then the sug-

\section{French agency to protect visiting posts}

Paris. The administrative council of France's Centre Nationale de la Recherche Scientifique (CNRS) last week unanimously endorsed the FFr13.3-billion (US\$2.7-billion) budget decided by the government for next year, even though this will allow no real increase in support for laboratory costs and will cut the recruitment of young scientists.

The members of the council, instead, appeared relieved that CNRS has been shielded by the research ministry from budgetary reductions approved by parliament in October for all government departments. "The situation is quite difficult, but it could have been worse," says Edouard Henri Brezin, chairman of the council. "Seen from the point of view of the major financial crisis which we faced last year, we are beginning to see the end of the tunnel."

But many researchers remain concerned. Funds for laboratory support, which make up 20 per cent of the total CNRS budget, are being reduced by 7 per cent, to FFr 2.6 billion. Hardest hit by this reduction will be newly created research teams and those working on novel research topics. Larger money from external sources will suffer less.

Similarly, the FFr10.7 billion promised for salaries is insufficient to maintain recruitment of researchers at the same level 261 research posts available in 1996, compared with 324 this year.

Brezin says that the administrative council has been looking at ways of maintaining its ability to accept foreign researchers in CNRS laboratories without reducing its support for French scientists. Until now, foreign postdoctoral students have been recruited to research posts only for short periods. Taking account of low number of such posts now available, foreign researchers will in future be supported out of a laboratory's own funds. But since these are also being reduced, the effect may still be a reduction in this type of scientific cooperation.

Catherine Tastemain laboratories that are better placed to raise as the rate of departure. There will be only gested $\$ 400$ million could be insufficient.

In particular, the worry is that, if roughly two-thirds of the proposed $\$ 400$ million contribution goes towards the cost of building and operating the LHC, this could leave insufficient funds to meet the experimental needs of US physicists planning to use the collider's two detectors.

Krebs and Llewellyn-Smith will try to reach agreement on the acceptable form of a potential US contribution before next autumn, when the Clinton Administration has to prepare its budget for the 1998 financial year. But any agreement they reach will still have to be endorsed by Congress.

Given the strength of isolationist sentiment in the House of Representatives, the scars left by what is regarded as the failure of foreign governments to support the abandoned Superconducting Supercollider (SSC), and the relative novelty of being asked to participate in a major international projects as a 'junior partner', that may well prove an even tougher obstacle than the negotiations themselves.

Colin Macilwain \& David Dickson

\section{Stanford accelerator announces staff cuts}

San Francisco. The Stanford Linear Accelerator Center (SLAC) in Menlo Park, California, is to shed between 60 and 70 staff jobs by next April, in anticipation of a \$7-million fall in the centre's operating budget for the fiscal year 1996. The cuts follow a decision by the Department of Energy to reduce SLAC's budget from \$107 million to $\$ 100$ million.

The lay-offs will reduce SLAC staff numbers from their current level of 1,350 to approximately 1,280. P. A. Moore, a spokeswoman for SLAC, says further redundancies depend "on what Washington has in mind". She claims that, although future reductions in staff numbers cannot be entirely ruled out, "we don't think they will be as severe as this". But some fear that the centre may eventually have to reduce its staff by up to 300 individuals.

SLAC officials have invited older staff to apply for early retirement to meet reductions intended primarily at reducing the operating overheads of the centre. But they also anticipate having to make some forced redundancies, as many of SLAC's older staff members took advantage of an early retirement scheme two years ago. "My guess is that we took most people at that cut," says Moore.

Nonetheless, Moore maintains that the lay-offs will not affect SLAC's present or future planned research programmes, including the construction of the B-factory that was approved last year. 